\title{
Educational Research in Primary Care: addressing the challenges through creation of a Special Interest Group and a Doctoral Student Network
}

\author{
Sophie Park ${ }^{1}$, Joe Rosenthal ${ }^{1}$ and Alexander Harding ${ }^{2}$ \\ ${ }^{1}$ Department of Primary Care and Population Health, ULC Medical School, London, UK \\ ${ }^{2}$ Sub Dean and Senior Academic Tutor, Peninsula College of Medicine and Dentistry, Exeter, UK
}

A journey of a thousand miles begins with the first step

\section{(Attributed to Lao Tzu circa 5 th century BCE)}

This month, we return to a key Hot Topic in the discipline of Academic Primary Care, namely recognising the essential role of Education and Teaching at the heart of excellence in primary care (Rosenthal et al., 2011).

\section{Introduction}

Two new groups within the Society of Academic Primary Care (SAPC) seek to respond to the challenges of providing high-quality collaborative research in primary care education. Here, we introduce the Special Interest Group in Educational Research (SIGER) along with the new Doctoral Student Network and consider their contribution to promoting the SAPC goal of research and teaching excellence within primary care in the United Kingdom.

\section{Background - the importance of Primary Care Education Research}

As health care has moved increasingly into the community, students have followed in large numbers, yet relatively little evidence is currently

Correspondence to: Dr Sophie Park, Department of Primary Care and Population Health, UCL Medical School, Hampstead Campus, Rowland Hill St., NW3 2PF, London, UK. Email: sophie.park@ucl.ac.uk

(C) Cambridge University Press 2012 available about teaching in this context. A number of key research questions exist (see Table 1) in addition to more broad research opportunities to explore inter-professional community-based teaching including continuing professional development and postgraduate training for GPs, nurses and allied healthcare professionals. Evidence concerning all these issues could inform primary care policy and ensure that we achieve high quality, as well as high quantity of education and practice in years to come.

\section{Challenges to providing high-quality Primary Care Education Research}

Educational Research in Primary Care has faced a number of internal and external challenges to date, including the scope and available time for research. Educational researchers have importantly often drawn upon a wealth of professional clinical and teaching expertise. They are, however, also faced with difficult tensions balancing demands for teaching, organisation and clinical service delivery, competing with dedicating energies towards research development. Projects have, therefore, tended to represent individual departmental achievements, rather than larger collaborative projects. Related educational researchers have had difficulty attracting major funders to provide protected research time (Cook et al., 2007; Todres et al., 2007). There are often considerable challenges in meeting the need frequently expressed by funding bodies to demonstrate direct relationships between education and patient outcomes. This often requires education to be conceptualised within a medical paradigm as an 'intervention' (Whitcomb, 2002), rather than 
Table 1 Key research questions for Educational Research in Primary Care

- Which teaching is best delivered in the community?

- What is the capacity of general practice and other sites; what are the workforce and space implications (Wallace et al., 2001)?

- What are the impacts of teaching involvement on clinical teachers, their service colleagues and most importantly their patients ( Hartley et al., 1999; O'Flynn et al., 1999)?

- What impact does learning within the primary care context have on students' professional development? How might it influence, for example, their clinical and communication skills (Howe, 2001); perceptions of community-based practice; team working and career choice (O'Sullivan et al., 2000)?

using a more sociological perspective to explore the 'work' that education does.

Given the volume and range of health-care teaching and training now taking place in the community, and the likelihood that this will increase in the future, this area of enquiry clearly requires further development and support. SAPC has recognised this challenge and has supported the establishment of an Educational Research Special Interest Group (SIGER) and Doctoral Research Network within the Society.

\section{Formation of new groups in response to these challenges:}

\section{Role of the SIGER}

The SAPC supports a number of special interest groups (SIGs) (SAPC, 2011), enabling members from a spectrum of disciplines and experience to come together to develop new relationships and collaborations supporting teaching and research agendas. Bringing together education and research experience has the potential to both maximise the use of innovative and suitable research methods to create and address challenging research questions, as well as inform research with existing experience. This might include promoting user involvement, relevance and utility as part of the research process; developing new and exciting methodologies to explore questions about complex learning processes within this context; and considering the translational gap throughout the research process, maximising the integration of relevant research findings to enrich community-based teaching delivery and practice.
Table 2 Purpose of the Doctoral Student Network

- Forum for discussion to promote support and encouragement from peers undertaking higher degrees related to educational research in primary care.

- Establish collaborative links across institutions.

- Share information about potential funding calls and applications

- Exchange of constructive and critical feedback with colleagues to develop work using a range of knowledge and ideological frameworks about relevant research questions, methodologies and potential integration into practice in this context.

The SIGER comprises both medical and nonmedical members interested in researching education in the primary care setting. Its aims are to:

- Provide a means for sharing ideas and innovations related to primary care clinical education.

- Encourage and facilitate the conducting of high-quality research in areas related to clinical education.

- Support the dissemination and implementation of clinical education research findings.

- Maintain liaison with other organisations with similar interests in clinical education or educational research.

- Support the training and education of educational researchers within SAPC (Rosenthal and McKinley, 2011).

By pursuing these aims, members will be better positioned to form a substantial contribution to SAPC conference presentations, attract major external long-term funding and produce highquality research to publish in a range of specialist and high-impact publications.

\section{Role of the Doctoral Student Network}

One of the recent initiatives of the SIGER has been to start developing a doctoral student network (see Table 2). This is currently a small group of SAPC members who are either considering, currently undertaking or have recently completed doctoral research in clinical education related to primary care. We are keen to expand this group, learn from each other and develop the agenda for research and expertise in this area. This includes strengthening links both with existing primary care researchers and with wider communities of educational researchers, such as the Research for Clinical 
Learning \& Practice Network and Association for the Study of Medical Education collaboration.

\section{How can I participate?}

For further information about the SIGER, please visit: http://www.sapc.ac.uk/index.php/specialinterest-groups/education-research

For more information about the doctoral student network, please contact sophie.park@ucl.ac.uk or alexander.harding@pms.ac.uk

\section{Conclusion}

The SIGER provides a further example of the SAPC's work to enhance primary care through academic excellence, promoting educational research as central to scholarship within Primary Care. It enhances existing links with academic primary care researchers, clinicians and teachers, as well as fostering fertile links with wider communities of practice in educational research.

\section{References}

Cook, D.A., Beckman, T.J. and Bordage, G. 2007: Quality of reporting of experimental studies in medical education: a systematic review. Medical Education 41, 737-45.

Hartley, S., Macfarlane, F., Gantley, M. and Murray, E. 1999: Influence on general practitioners of teaching undergraduates: qualitative study of London general practitioner teachers. British Medical Journal 319, 1168-171.

Howe, A. 2001: Patient-centred medicine through studentcentred teaching: a student perspective on the key impacts of community-based learning in undergraduate medical education. Medical Education 35, 666-72.

O'Flynn, N., Spencer, J. and Jones, R. 1999: Does teaching during a general practice consultation affect patient care? British Journal of General Practice 49, 7-9.

O'Sullivan, M., Martin, J. and Murray, E. 2000: Students' perceptions of the relative advantages and disadvantages of community-based and hospital-based teaching: a qualitative study. Medical Education 34, 648-55.

Rosenthal, J., and McKinley, B. 2011: Educational research [Online]. Society of Academic Primary Care (SAPC). Retrieved 14 October 2011 from http://www.sapc.ac.uk/ index.php/special-interest-groups/education-research

Rosenthal, J., McKinley, B. and Pearson, D. 2011: Promoting education within the SAPC: introducing the HOTs group. Primary Health Care Research and Development 12, 276.

SAPC. 2011: Society of Academic Primary Care. Retrieved 3 November 2011 from http://www.sapc.ac.uk/index.php/ special-interest-groups

Todres, M., Stephenson, A. and Jones, R. 2007: Medical education research remains the poor relation. British Medical Journal 335, 333-35.

Wallace, P., Berlin, A., Murray, E. and Southgate, L. 2001: CeMENT: evaluation of a regional development programme integrating hospital and general practice teaching for medical undergraduates. The CommunityBased Medical Education in North Thames. Medical Education 35, 160-66.

Whitcomb, M.E. 2002: Research in medical education: What do we know about the link between what doctors are taught and what they do? Academic Medicine 77, 1067-68. 